\title{
A feasibility study of the Master SN curve approach for short fiber reinforced composites
}

Atul Jain ${ }^{*}, 1,2$, , Wim Van Paepegem ${ }^{3}$, Ignaas Verpoest ${ }^{2}$, Stepan V. Lomov²

1. Siemens Industry Software NV, Interleuvenlaan 68, B-3001 Leuven

2. Department of Materials Engineering , KU Leuven, Belgium;

3. Department of Material Science and Engineering, Ghent University, Belgium

*corresponding authoremail: atulatj@gmail.com/atuljain@usc.edu

${ }^{\dagger}$ Current affiliation: M.C. Gill Composites Center, University of Southern California.

Abstract: Short fiber reinforced composite (SFRC) materials have a different fiber orientation distribution (FOD) at every point. The fatigue properties of SFRC are known to depend on the FOD. The Master SN curve (MSNC) method for predicting an SN curve for a given FOD based on the known SN curve for the reference FOD is used to predict the local SN curve of a SFRC component by relating the damage at the microscopic level to the macroscopic fatigue properties. A simplified version of MSNC method, which needs even less experimental input, uses an assumption of constant SN curve slope is also presented in this paper. The paper validates both variants of the MSNC method on three sets of experimental data on fatigue of short fiber composites and analyses their accuracy. It is demonstrated that the MSNC approach needs only one SN curve as input with no specific requirements to the fiber orientation of the test coupon. Test coupons could have either uniform fiber orientation in the thickness or a "skin core" orientation variation.

\section{Highlights:}

- A method for generating local SN curves for short fiber composites is presented

- Method is based on combination of manufacturing studies, tests and micromechanics

- Slope of SN curve is found to be independent of fiber orientation distribution(FOD)

- Only one SN curve is needed as input with no restriction on FOD of reference coupon

\section{Introduction}

Injection molded short fiber reinforced composites (SFRC) hold great promise for use in several industrial applications. This is due to the ease of large scale manufacturing and reasonable specific properties. Despite all the promises held by SFRC, their use in industry today is rather limited. This can be ascribed to the reason that reliable simulation methods for functional performances such as durability 
are not commonly available. Also the prevalent simulation methods are mostly test based and require a large amount of experimental data as input. Collecting experimental data is often seen as a bottleneck during fatigue simulation of composite materials.

Fatigue behavior of injection molded composites depends on a number of factors like fiber orientation distribution (FOD), mean stress corrections etc. For a good summary of the different factors on which the fatigue behavior of SFRC can depend, the reader is referred to a recent review [1]. In this paper we focus entirely on the prediction of the dependence of the fatigue behavior on the fiber orientation distribution (FOD).

Injection molding processes lead to different FOD at every point. The FOD can be determined at every point by both experimental techniques [1,2] and simulation software [4]. However according to Horst et al. [5] correct calculation of the FOD is only a first step toward fatigue simulation of SFRC. It is important to understand the relation between the FOD and the fatigue properties. A number of experimental results [6-15] have confirmed the dependence of the fatigue and static behavior on the FOD of the tested specimen. However, the exact relation between the fatigue properties and FOD is unknown.

For a component-level simulation, each point in the FE model has a known statistical distribution of length and orientation of fibers which is often predicted by using manufacturing simulation tools. Each point in the FE mesh can therefore be imagined as a different material whose static and fatigue properties need to be estimated [16]. For an RVE, one can calculate the effective static properties of the composite by a number of different methods, for example the Mori-Tanaka (MT) formulation [17]. However, unlike elasticity there are no well understood and universally accepted formulations to describe fatigue, thus there is an absence of an analytical method to predict the SN curve of a composite material. There have been some attempts to estimate the local SN curve of SFRC material. One popular approach is to normalize the fatigue strength based on the ultimate tensile strength (UTS). This approach is based on experiments that showed the proportionality of both properties $[1,6,9,12,18,19]$. However, there is no physical reasoning as to why the fatigue strengths must vary in the same manner as the tensile strength, there are experimental evidences which confirm that the failure mechanisms for damage propagation and final failure are different during tensile and fatigue loading $[5,10,12]$. Also the damage 
mechanisms of some glass fiber reinforced semi-crystalline polymers could depend on the strain rate $[20,21]$. It was recently shown that the UTS based scaling can lead to unreliable predictions [15].

Other approaches include scaling the SN curve on the basis of the fatigue crack growth parameter $[8,19$, 22], this approach gives reasonable results. However this approach requires as input apart from one SN curve, a fatigue crack growth parameter. Meneghetti et al. [23] and Jegou et al.[24] proposed a method for SN curve prediction of SFRC based on the specific heat dissipation due to damage propagation. Both these approaches require rather extensive and difficult tests.

In the absence of a reliable method for estimating the SN curve, the standard practice in fatigue simulation of SFRC is to make simplifying assumptions about the relation between the FOD and fatigue properties of SFRC. Several SN curves are experimentally derived and a test based interpolation [25] (or "reverse engineering" [26]) is usually employed to generate the SN curves at different points. Such methods depend on a number of tests on coupons with extreme FOD. Furthermore it is almost impossible to create test coupons with perfect extreme alignment therefore some extrapolation might be needed as well. Other approaches include use of empirical reduction factors for different factors like FOD, length, notch, mean stress etc. such an approach is often used for polymers [27]. A similar approach which requires an extremely large number of tests was tried by Guster et al.[13] and Mosenbacher et al.[28] for the simulation of SFRCs.

Recently, the authors of this paper developed a "Master SN Curve approach", in short MSNC [15]. This MSNC approach was used to predict the local SN curve of SFRC components by relating the damage at the microscopic level to the macroscopic fatigue properties. The input for the calculations was one SN curve of the test coupon, the elastic properties of the fiber and the matrix, and the stress-strain curve of the matrix. This methodology depends on manufacturing simulation and tests (hybrid approach) and also mechanics on different scales (multi-scale).

In the present paper the MSNC algorithm is validated using three sets of published experimental data. It is shown that the scheme has little restriction on the FOD of the test coupon whose SN curve is to be used as input. MSNC scheme is shown to work for coupons which have non-uniform distribution of FOD through the thickness as well as coupons with uniform FOD. 
The accuracy of the proposed method could depend on two input parameters, the FOD of the reference SN curve and the chosen number of cycles to failure. The dependence of the accuracy of the MSNC method on the two parameters is studied and recommendations are made for proper usage of the MSNC approach.

Additionally, a new variant of the MSNC idea is proposed which is computationally cheaper and needs less input; it assumes a constant slope of S-N curve. The new assumptions are validated and the accuracy of the two variants of the MSNC algorithm are compared.

The theory of the MSNC approach is recalled in section 2. Section 3 describes the numerical implementation and the details of the three sets of experimental data used for the validations. Section 4 is devoted to the results and discussion while the conclusions are derived in section 5 .

\section{Theory}

\subsection{Master SN Curve approach}

A detailed description of the theory and assumptions behind the MSNC method has been presented in a previous paper [15], the key points of the MSNC approach are recalled here for sake of completeness.

Like all composite materials, fatigue failure of SFRC generally occurs when cracks are developed to a sufficient extent enough to cause final failure. Under uniform cyclic loading, single fiber matrix debond cannot be sufficient to cause failure of SFRC. In the proposed MSNC approach the extent of damage is quantified as the loss of modulus in the applied loading direction. It is then assumed that for SFRC with different FOD and fiber length distribution (FLD) but same constituents (fiber and matrix), the extent of damage needed to propagate and cause final failure during uniform cyclic loading must be similar. In other words, it is assumed that the damage propagation (and subsequent loss of stiffness) during cyclic loading in SFRC is similar.

It is known that RVE's with different FOD and different FLD have a different stress to failure for a certain number of cycles. But the stiffness degradation curve is assumed to be similar. This is the key assumption of the MSNC. A thorough statistical treatment confirming that the loss of stiffness curves during cyclic loading are independent of the FOD have been presented in a separate paper [29]. 
1. The number of cycles, $\mathrm{N} 1$ and corresponding stress to failure, $\mathrm{S} 1$ information is extracted from the reference SN curve.

2. The initial modulus of the reference coupon RVE, $E_{0}$ is calculated using the MT formulation.

3. Micromechanical modelling involving matrix non-linearity and /or fiber matrix debonding is performed and secant modulus, at $E_{1}$ is calculated at load S1.

The details of the micromechanical modelling are given in the section 2.2.

4. Damage parameter, $d$ is calculated based on the steps 2 and 3 using the formula:

$E_{1}=E_{0}(1-d)$

Where, $E_{1}$ is the Young's modulus of the RVE in the axial direction after the first half cycle of load, while $E_{0}$ is the initial Young's modulus and $d$ is the value of the damage parameter.

5. The initial Young's modulus of the target RVE (RVE whose SN curve is to be determined) is calculated.

6. Small stress increments are added, the modulus and subsequently the damage parameter is calculated at the end of every step.

7. The stress, S2 at which the damage parameter for target RVE equals the damage parameter previously calculated for the reference RVE is the corresponding stress for the same number of cycles.

The above described steps can be repeated for as many points as needed to generate data points in the SN curve.

In this model, it is not needed to model the evolution of damage (defined as loss of secant modulus) for different cycles of loading. Only the first cycle of loading is modelled and the local SN curves are derived based on the calculated damage parameter and one input SN curve. 


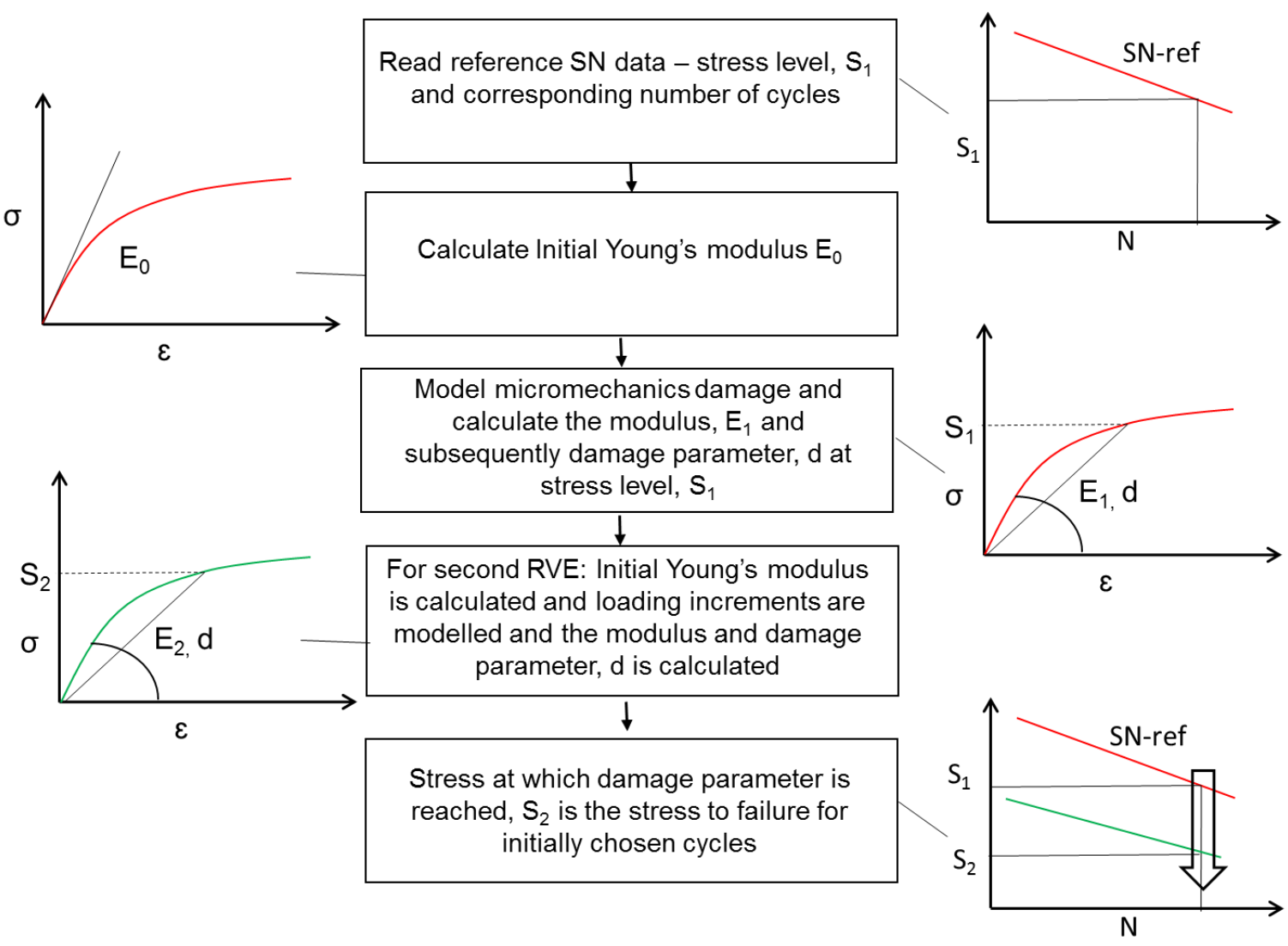

Figure 1 A step by step schematic representation of the MSNC algorithm

\subsection{Micromechanical modelling}

Effective stiffness of a random fiber composite and stress-strain state of the individual fibers under the first cycle loading is calculated using Mori-Tanaka mean field scheme for homogenization and calculation of strain concentration tensors $[17,30]$, applied to the full assembly of the fibers in the representative volume. The latter is randomly generated according to the FOD and FLD of the composite. Each fiber is represented by an ellipsoidal inclusion with its own aspect ratio, orientation and volume. We have demonstrated that this algorithm correctly calculates the homogenized elastic properties of the composite and that the stresses in fibers [31] and on the fiber-matrix interface [32] are calculated with an acceptable accuracy. We also have proven that for typical random fiber composites the degree of asymmetry of the stiffness tensor predicted with Mori-Tanaka method is limited and simple symmetrisation of the stiffness tensor provides an acceptable correction [33]. 
Micromechanical damage modelling of SFRC is done at the constituent level, i.e., modelling the damage of the fibers and the matrix. It is known that there are two sources of damage in SFRC, namely, fiber matrix debonding and matrix damage. The length of fibers in SFRCs is often too short to result in fiber breakage.

The Mori-Tanaka formulation can be used only for linear elastic constituents. To overcome this short coming, the concept of "reference material" is introduced. Matrix non-linearity is calculated based on the secant modulus approach [34]. In this approach the average strain in the matrix is derived by the MT formulation and the secant modulus of the matrix subject to a given strain is calculated on the basis of the stress-strain curve of the pure matrix. At the end of every load step, the matrix is replaced by the reference material. The modulus of the reference material is the secant modulus of the matrix which has been calculated based on the stress strain curve of the pure matrix.

Onset for fiber matrix debonding is calculated using Modified Coulomb's criteria which accounts for both normal and tangential stresses at the interface. Mathematically the interface is said to be debonded if the following criterion is satisfied:

$\sigma_{N}+\beta \tau \geq \sigma_{y}$

Where, $\sigma_{N}$ and $\tau$ are the normal and tangential stress component at the interface. $\beta$ is the shear contribution co-efficient. $\beta$ is an empirical quantity whose value is taken to be 0.5 [35]. $\sigma_{y}$ is the yield strength of the matrix. A detailed description of the Modified Coulomb criteria and its application to ellipsoidal inclusions is presented in [35].

Fibers with debonded interface are treated by replacing the debonded fibers by an "Equivalent Bonded Inclusion" in short $E q B I$. The diagonal terms, $C^{\prime}{ }_{i i}$ of the stiffness tensor of the $E q B I$ are determined as a product of (i) the corresponding diagonal terms $\left(C_{i i}\right)$ of the stiffness tensor of the original inclusion and (ii) the ratio of the average stress in the inclusion with debonded interface $<\sigma_{i i}^{\prime}>$ to the average stress that would be built up in the inclusion, if it was perfectly bonded $<\sigma_{i i}>$ :

$C^{\prime}{ }_{i i}=\frac{\left.<\sigma_{i i}^{\prime}\right\rangle}{<\sigma_{i i}>} C_{i i}$

where $C^{\prime}{ }_{i i}, C_{i i}$ are the stiffness component of the $E q B I$ and the original inclusion which relates the average stress $\sigma_{i i}$ in a composite to the applied strain $\varepsilon_{i i}, \sigma_{i i}^{\prime}$ and $\sigma_{i i}$ are stresses in the inclusion with 
debonded and perfect interface respectively; $<>$ indicates volume averaging. The input for such modelling is the yield stress of the matrix.

Based on the region of the debonding, they have been classified into two groups: Type A for tip debonding and Type B for debonding elsewhere. For loading in the axial direction of the fiber direction and Type A debonding, the Cox formulation [36] is used. While for the other types of loading, simple stress redistribution rules have been developed. Expressions for the stress distribution for an inclusion with debonded interface scheme are presented in table 1, detailed derivations and FE validation of the proposed " $E q B I$ " can be found in [32].

Sometimes coupons manufactured from an injection molded plate or a part have a variable fiber orientation distribution through the thickness due to the "skin-core" effect [37]. An example of the skin core variation of the FOD has been presented in section 3.2.3 and Figure 4a. Such coupons are modelled by treating each layer separately and assuming that the layers are subject to the same strain (iso-strain assumption). The number of layers which must be considered for the MSNC approach are dependent of the number of layers considered during manufacturing simulation or experimental characterization. During manufacturing simulation, typically a sensitivity analysis is performed to ascertain the number of layers. The effective response of the coupon is then calculated by the thickness weighted average of the stiffness of each layer. 
Table 1 A summary of the expressions of the stresses in inclusions with debonded interface, $\boldsymbol{\sigma}_{\text {incl. }}^{\prime}$. The stiffness of the EqBI is calculated as a function of the reduced stress in the inclusion with the debonded interface

\begin{tabular}{|c|c|c|}
\hline $\begin{array}{c}\text { Stiffness } \\
\text { component }\end{array}$ & Type A & Type B \\
\hline $\mathrm{C}_{\mathrm{zz}}$ & $\begin{array}{l}\sigma_{\text {incl }}^{\prime}=E_{\mathrm{f}} \cdot \varepsilon_{1}-\left(\mathrm{E}_{\mathrm{f}} \cdot \varepsilon_{1}-2 \cdot \tau_{\mathrm{i}} \cdot \mathrm{s} \cdot \mathrm{m}\right) \cdot \frac{\cosh \left(\frac{\mathrm{nz}}{\mathrm{r}}\right)}{\cosh (\mathrm{n} \cdot \mathrm{s}(1-\mathrm{m}))} \\
\text { where, } \tau_{\mathrm{i}}=-\mu\left(\sigma_{\mathrm{res}}-v_{1} \cdot \mathrm{E}_{\mathrm{m}} \cdot \varepsilon_{1}\right) \text { and } \mathrm{n}^{2}=\frac{2 \cdot \mathrm{G}_{\mathrm{m}}}{\mathrm{E}_{\mathrm{f}} \cdot \ln \frac{\mathrm{R}}{\mathrm{r}}} \\
\text { Average stress is calculated by integration over length of inclusion, } z ; \\
E_{f}, \nu_{1} \text { are the Young's modulus and Poisson's ratio of the inclusion, } \varepsilon_{1} \text { is the remote applied } \\
\text { strain and } \tau_{i} \text { is the shear stress in the interface. } \sigma_{\text {res }} \text { is the residual stress in the interface, } m \text { is the } \\
\text { fraction of the inclusion which has debonded interface and } \mathrm{z} \text { is the coordinate of the inclusion } \\
\text { in the axial direction with the centroid as origin } \\
G_{m} \text { is the shear modulus of the matrix and the term } R / r \text { is the ratio of the radius of the VE and } \\
\text { fiber }\end{array}$ & No change in average stress \\
\hline $\mathrm{C}_{\mathrm{yy}}$ & \multicolumn{2}{|c|}{$\begin{array}{l}\sigma_{\text {incl }}^{\prime}=\sigma_{\mathrm{f}} \text { if interface is perfect } \\
\sigma_{\text {incl }}^{\prime}=0 \text { if interface is debonded } \\
\text { Average stress is calculated by volume weighted averaging } \\
\sigma_{f} \text { is the average stress in the inclusion that would be present if there was perfect interface in the inclusion }\end{array}$} \\
\hline
\end{tabular}




\subsection{Variations of the MSNC algorithm}

The first possibility of implementing the MSNC approach is to perform micromechanical modelling by accounting for both matrix non-linearity and fiber matrix debonding and calculate the damage parameter based on loss of stiffness due to both these events. In this approach, the damage parameter is a function of both damage in the interface as well as matrix. This MSNC approach can then be implemented based on this damage parameter. By this method the stress to failure can be estimated for at least three different numbers of cycles to failure and then fit the predicted results to a suitable equation to generate the SN curve. This implementation of the MSNC approach needs as input one SN curve, the stress strain curve of pure matrix including the value of yield stress.

A second possibility is to perform the micromechanical modelling by accounting for only fiber matrix debonding, calculating the damage parameter and subsequently implementing the MSNC algorithm based on this damage parameter. In this approach, the damage parameter is a function of only damage in the interface. The MSNC algorithm is then implemented for only one point (preferably high cycle fatigue where the applied load is low and the damage in the matrix is also low) and then the SN curve is generated assuming that the slope of the SN curve is independent of the FOD. This MSNC formulation is named "same-slope MSNC" or in short, "ss-MSNC". The input for this formulation is one SN curve and the yield stress value of the pure matrix. For this approach it is no longer necessary to have the stress-strain curve of the pure matrix. This is an important advantage since the stress-strain curve of the pure matrix can be hard to get, particularly if the pre-compounded glass pellets are used during the injection molding process. Typically, the glass fiber is pre-compounded in the matrix and supplied by the material supplier as pellets. In such cases it can be difficult to get the stress strain curve of the pure matrix. A schematic representation of the two variations of the MSNC approach has been shown in Figure 2. 


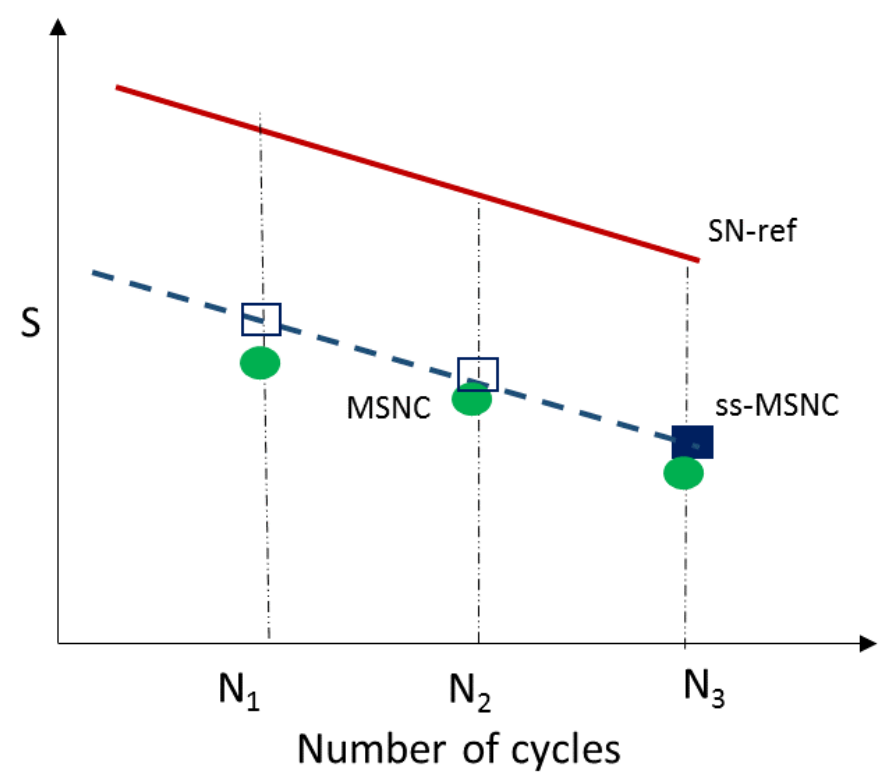

Figure 2 A schematic representation of the MSNC and ss-MSNC approach. In the MSNC approach, different points of the SN curve are estimated by equating the damage parameter (green oval marker), while in the ss-MSNC approach only one point is estimated by equating the damage parameter (solid rectangular blue marker) and other points (hollow rectangular blue markers) are extracted assuming same slope (dotted blue line) as the reference SN curve

It is clear that the same-slope MSNC approach needs less input and is also computationally less expensive. In this approach, the only matrix related input is the yield stress of the matrix, the stress strain curve of the matrix is no longer needed.

However, two additional assumptions are introduced in this variation of the MSNC approach. First it is assumed that at low stresses, damage in the matrix is minimal. It is known that the extent of damage due to matrix non-linearity is rather limited when low stresses are applied and it progressively increases. Whereas fiber matrix debonding starts occurring at low stresses and is the primary source of damage at small applied load. This was recently reported by in-situ experiments [20] and also demonstrated numerically [32].

The second assumption is that the slope of the SN curves is independent of the FOD. This assumption must be validated before proceeding with this same-slope MSNC variation of the algorithm.

\subsection{Same slope assumption}


There is some confusion in literature with regards to the variability of the slope of the SN curves for SFRCs with different FOD. Guster et al.[13] claim that there is a strong dependency of the slope of the SN curve on the FOD, while Launay et al.[38] remark that the slopes are independent of the FOD. The different slope in the SN curves, reported for certain experimental series, could be due to the scatter in the number of cycles to failure, indicating that the number of tests is not sufficient for a good statistics. For an applied load, there is a scatter in the observed number of cycles to failure. Assuming normal distribution of the cycles to failure for a given load, the statistical significance of the difference in slopes of two SN curves can be assessed using Student's t-tests [39]. In this paper the published fatigue data is collected for nine sets of fatigue data which is used to validate the same slope assumption.

In each of the nine papers considered here (see section 4.1), there were two or more SN curves reported for SFRC coupons with different FOD, but with the same fibrous composition. When there are more than two SN curves which need to be compared, then the set of SN curves are compared by taking two curves at a time and repeating the calculations for every combination. If there are " $w$ " number of SN curves for a certain material, the statistical comparison has to be repeated $w(w-1) / 2$ number of times. All comparisons of the slopes are performed at 95\% significance level.

\section{Numerical implementation and details of selected data}

\subsection{Numerical implementation}

In this sub-section the details of the numerical implementation are provided.

\subsubsection{MSNC implementation}

For implementing the MSNC approach, first a realization of the RVE is created from the $2^{\text {nd }}$ order orientation tensor by the methods proposed by Onat and Leckie [40]. For all the calculations presented in this paper the size of the RVE is 2000 inclusions. The MT formulation has been used for homogenization. A modified Coulomb criterion is used to determine the onset of fiber matrix debonding. Onset of debonding is checked at 100 points along the three cross orthogonal cross section of the ellipsoid. Debonded fibers are treated by replacing them with an equivalent bonded inclusion $(E q B I)$. The strain increment for all the calculations is taken to be $0.01 \%$.

The MSNC approach is validated for three sets of experimental data, published by Jain et al. [15], De Monte et al. [6] and Klimkeit et al. [8]. In each of the three sets of data one SN curve at a time is taken 
as the reference SN curve and the other SN curves are predicted and compared with the experimental results. The validation is repeated for every SN curve reported. Skin-core effect of coupons reported by Klimkeit et al. [8] is modelled by treating each layer separately and then assuming iso-strain conditions across different layers.

Two sets of calculations are performed: in the first set, the validation of the proposed MSNC approach is performed at three different numbers of cycles to failures: $10^{4}, 10^{5}$ and $10^{6}$ cycles. Both fiber matrix debonding and matrix non-linearity are considered.

In the second set of calculations, the ss-MSNC approach is validated. For this study, only fiber matrix debonding is considered and the different points are generated using the same slope assumption. In this case the MSNC approach is implemented for $10^{6}$ cycles.

\subsubsection{Error analysis}

The predictions of the MSNC approach are compared with the experimental values and the error is calculated for each of the predicted points. The error $\left(e_{f}\right)$ is defined as follows:

$e_{f}=1-\frac{\text { Predicted stress by } M S N C}{\text { Experimental value }}$

For the error analysis, the simulations performed in this paper are grouped according to two different criteria. First basis of classification is the FOD of the input SN curve, while the second basis is the input number of cycles to failure.

Based on the FOD of the input SN curve, the predictions of the MSNC approach for the three sets of data are grouped in three groups. The first group comprises the cases where the input $\mathrm{SN}$ curve has primary orientation of fibers in the load direction; the second group consists of predictions based on input SN curve with orientations close to 45 degree while the third group was the predictions based on 90- degree coupons.

Next the effect of the chosen number of cycles to failure was examined. Based on the chosen number of cycles to failure, the predicted points were grouped in three categories viz. $10^{6}$ cycles, $10^{5}$ cycles and $10^{4}$ cycles. 
Two statistical quantities are calculated for each group: The standard deviation and the mean of the error. Using the two above values, it is determined whether the magnitude and the variance of the error depend on the FOD of the input SN curve coupon and on the number of cycles that is taken as input.

\subsection{Collected data}

In this section the three sets of data used for the validation of the MSNC approach are recalled. Each of the three papers provide enough details for the RVE reconstruction and also the properties of the fiber and the matrix. However the stress-strain curve of the matrix which is needed as input for the MSNC method was not available. The stress-strain curve of the matrix has been chosen on the basis of having the Young's modulus (and density where applicable) given for the polymer in question in the database of CAMPUS plastics [41]. The stress-strain curve of two different grades of the same polymer but having the same elastic modulus is not expected to vary too much.

Each of the three sets of data used in this paper represent the FOD in terms of the second order orientation tensor. A brief introduction to the orientation tensor is provided below. This concept of orientation tensor was developed by Advani and Tucker [42].

The second order orientation tensor, typically represented as $a_{i j}$. Mathematically,

$a_{i j}=\sum_{i=1}^{M} p_{i} p_{j}$

Where, $\mathrm{M}$ is the total number of fibers and $p$ is the orientation vector of individual fiber which is defined as follows:

$p_{1}=\sin \theta \cos \phi$

$p_{2}=\sin \theta \sin \phi$

$p_{3}=\cos \theta$

$\theta$ and $\phi$ are the Eulerian angles.

At this stage it is important to note that the models described in this paper are not limited only to second order orientation tensor description of the FOD. The starting point of this model is a realization of the RVE, which can also be created if the FOD is described in the form of an orientation distribution function [43] or any other means.

\subsubsection{Jain et al.}


Jain et al. [15] performed fatigue tests on coupons which were milled in 0,45 and 90 degree directions out of a plate having dimensions $170 \times 170 \times 2 \mathrm{~mm}$. For the rest of the paper, the coupons are referred to as 0,45 and 90 degree coupons respectively. The applied load ratio was 0.1 .

They used 50\% weight fraction glass fiber (GF) reinforced Polybutylene terephthalate (PBT). The Young's modulus for the glass fiber and the matrix was given to be 72 and 2.6 GPa respectively while the Poisson's ratio is 0.22 and 0.37 , and the yield strength of the matrix is taken to be $55 \mathrm{MPa}$. The average aspect ratio of the fiber is 26 . The stress-strain curve for the matrix is taken to be the same as BASF Ultradur ${ }^{\circledR}$ B 4500 (Figure 3), this PBT matrix is from the same material supplier and has the same modulus as reported by the Jain et al.

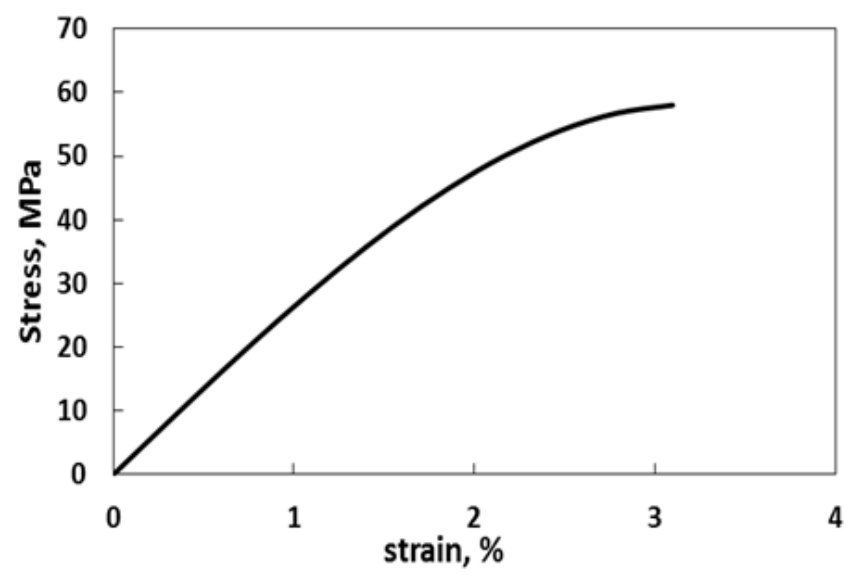

Figure 3 Stress strain curve of BASF Ultradur ${ }^{\circledR}$ B 4500 [41]

The orientation distribution was represented using the second order orientation tensor which was found to be more or less uniform in the thickness of the plate. The orientation tensor of the 0-degree coupon was calculated (by using manufacturing simulation software SIGMASOFT[44]) to be

$$
a_{i j}=\left[\begin{array}{ccc}
0.81 & 0.018 & 0.137 \\
0.018 & 0.11 & 0.004 \\
0.137 & 0.004 & 0.079
\end{array}\right]
$$

The orientation tensor of the 45 and 90 -degree coupons were calculated by rotating of the $0^{\circ}$ orientation tensor.

\subsubsection{De Monte et al.}

De Monte et al. [6,45] performed fatigue tests on coupons which were milled in 0, 30 and 90 degree directions out of a plate. For the rest of the paper, the coupons are referred to as DM-0, DM-45 and DM- 
90 degree coupons respectively. They used 30\% weight fraction GF reinforced poly-amide (PA) 6, 6 . The average aspect ratio of the fiber was 26 . The strength of the matrix is taken to be $83 \mathrm{MPa}$ [41]. The Young's modulus for the glass fiber and the matrix was given to be 72 and $3.1 \mathrm{GPa}$ respectively while the Poisson's ratio was 0.22 and 0.4 .

The orientation distribution was represented using the second order orientation tensor which is was found to be more or less uniform in the thickness of the plate and equal to 0.79 (Figure 4). The value of the $\boldsymbol{a}_{11}$ has been provided in the paper, while the other components of the orientation tensor are missing. Since the thickness of the plate is small $(1 \mathrm{~mm})$, it was assumed that the FOD is 2-dimensional. Therefore, $a_{22}$ was taken to be equal to $1-a_{11}$ and the value of $a_{33}$ is set to zero.

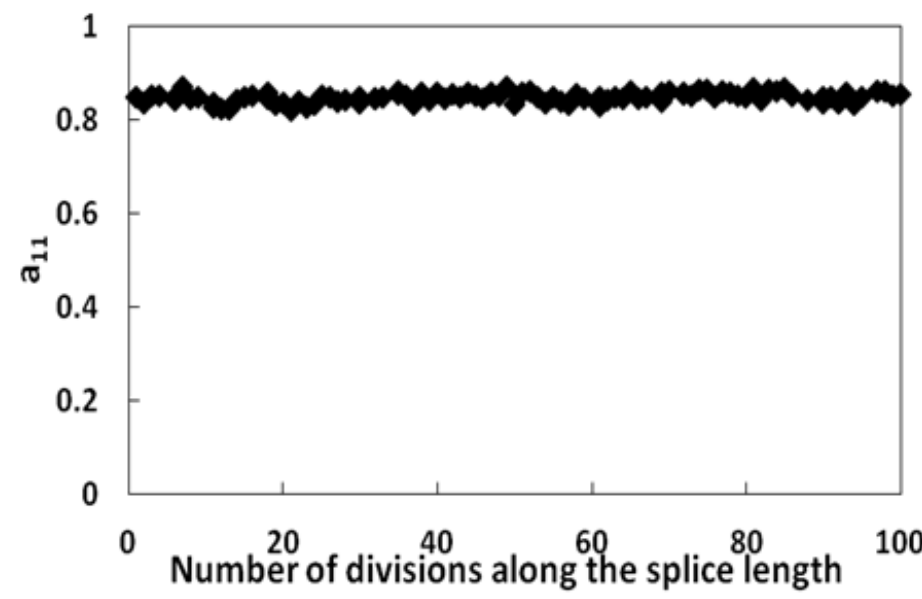

$a$

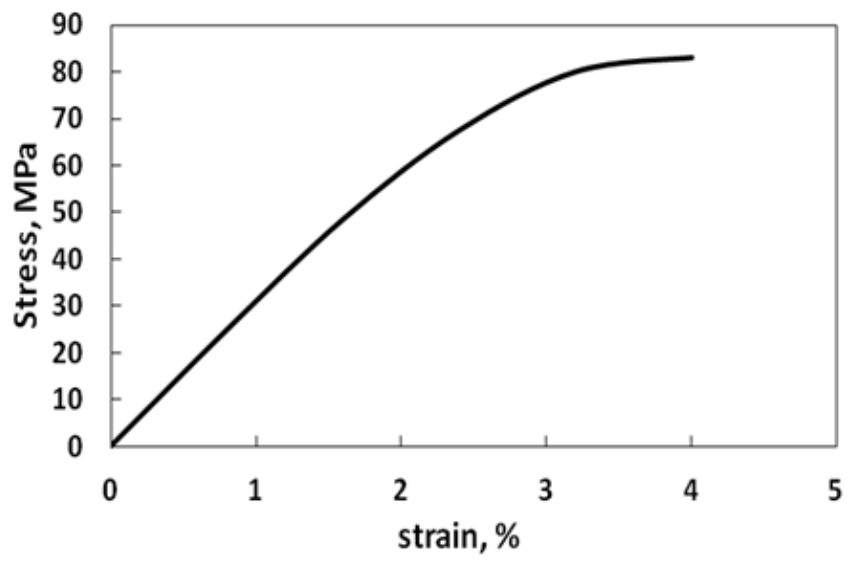

Figure 4 Input details for data by De Monte et al. (a) Variation of the second order orientation tensor component $a_{11}(\boldsymbol{b})$ Stress strain curve of matrix Zytel ${ }^{\circledR}$ E42A NCO10 
Unlike the two other sets of validations considered in this paper which had an applied load ratio of 0.1 , fatigue tests by De Monte et al. were performed at an applied load ratio of 0 . The stress strain curve of the matrix which is needed for the analysis presented in this paper was not provided in the paper. The properties of the matrix are taken to be the same as polyamide - Zytel ${ }^{\circledR} \mathrm{E} 42 \mathrm{~A} \mathrm{NC010}$ (Figure 4b); this polyamide matrix has exactly the same modulus and density as reported in the paper by De Monte et al.

\subsubsection{Klimkeit et al.}

Klimkeit et al. [8] performed fatigue tests on coupons which were milled from flat plates in 0, 45 and 90 degree directions with respect to the flow of the matrix and tube shaped coupons. In the rest of the paper, the coupons are named KK-0, KK-45 and KK-90 for the 3 coupons milled at 0, 45 and 90 with respect to the flow direction of the matrix. The tubular coupon is named KK-tube.

They used 30\% weight fraction GF reinforced PBT. The average aspect ratio of the fibers is given to be 23. The Young's modulus for the glass fiber and the matrix is given to be 72 and 4 GPa respectively while the Poisson's ratio is 0.22 and 0.35 . The yield strength of the matrix is $58 \mathrm{MPa}$.

In addition to the stress-strain and SN curves of SFRC coupons, the details of the orientation tensor $a_{11}$, $a_{22}$, and $a_{33}$ were also provided. The FOD was calculated using manufacturing simulation software MoldFlow [46]. The orientation distribution was seen to follow a "skin core" variation across the thickness in the plates (Figure 5a), while there was less variation in the value of the orientations for the tubes (Figure $5 \boldsymbol{b}$ ). The authors of the paper used 21 layers through the thickness during the manufacturing simulation.

For the analysis in this paper, the properties of the matrix are taken to be that of PBT material Arnite ${ }^{\circledR}$ T06 200 (Figure 5c). This PBT matrix has the same modulus as reported in the paper. 

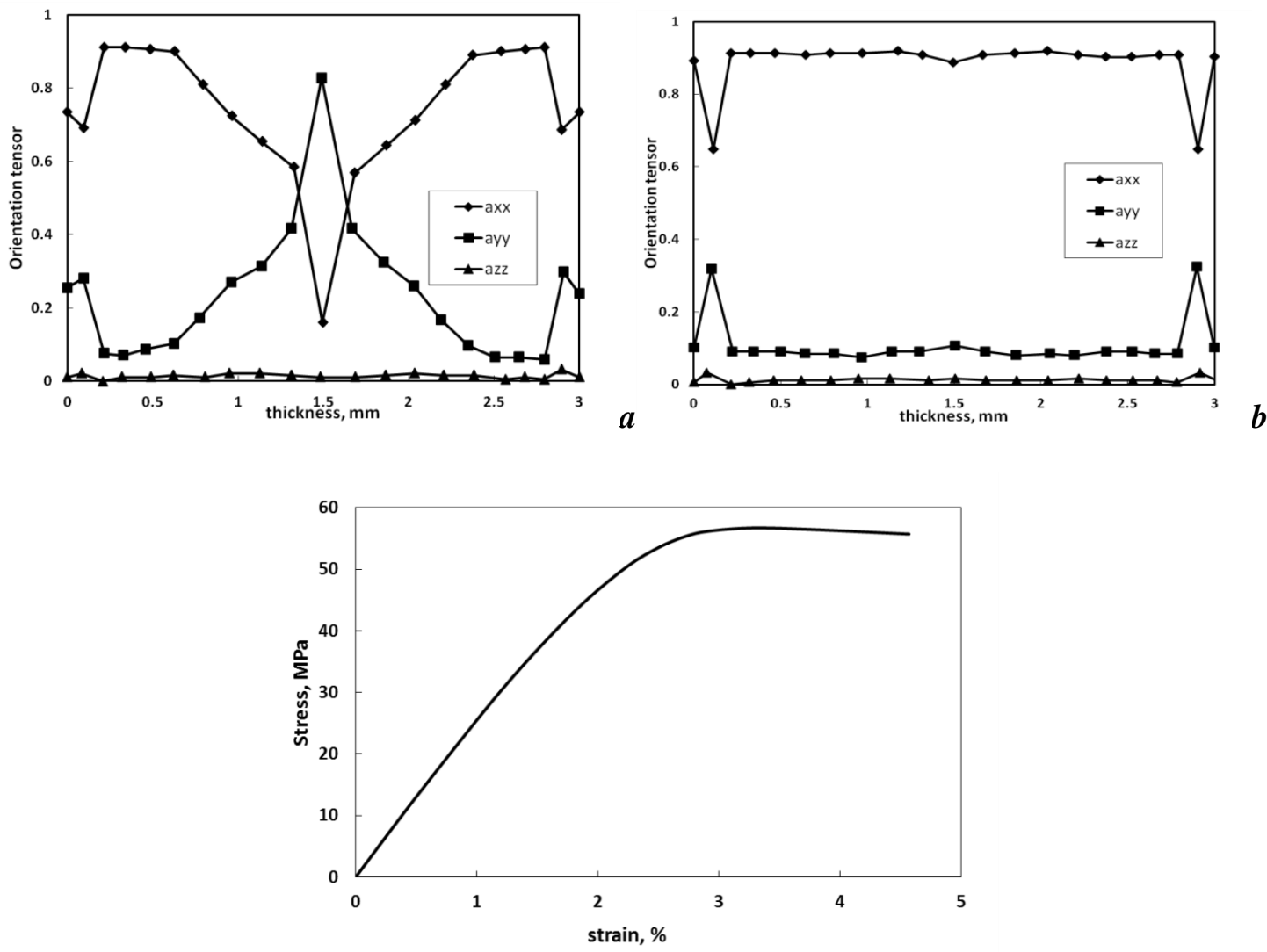

Figure 5 Input details for data by Klimkeit et al. (a)Variation of the orientation tensor in the thickness of the plate and (b) tube[8], (c) Stress-strain curve of PBT matrix Arnite ${ }^{\circledR}$ T06 200.

The details of the three papers are summarized in Table 2. 
Table 2 Description of three collected fatigue data used for the validation of the MSNC method

\begin{tabular}{|c|c|c|c|c|c|c|c|c|}
\hline & $\begin{array}{l}\text { Source of } \\
\text { data }\end{array}$ & Material & $\begin{array}{l}\text { Method of varying } \\
\text { the orientation }\end{array}$ & $\begin{array}{l}\text { Description of Orientation } \\
\text { distribution of inclusions }\end{array}$ & $\begin{array}{l}\text { Average } \\
\text { aspect } \\
\text { ratio }\end{array}$ & $\begin{array}{l}\text { Elastic } \\
\text { Properties of } \\
\text { the fiber } \\
\text { [E ( GPa), } \\
\text { Poisson's } \\
\text { ratio] }\end{array}$ & $\begin{array}{l}\text { Elastic } \\
\text { Properties of } \\
\text { the matrix } \\
{\left[E_{1}(\mathrm{GPa}),\right.} \\
\text { Poisson's } \\
\text { ratio] }\end{array}$ & $\begin{array}{l}\mathrm{R}- \\
\text { ratio }\end{array}$ \\
\hline 1 & Jain et al. & $\begin{array}{l}50 \% \text { wt. } \\
\text { glass fiber } \\
\text { (GF) } \\
\text { reinforced } \\
\text { PBT }\end{array}$ & $\begin{array}{l}\text { Coupons are } \\
\text { milled in different } \\
\text { directions from a } \\
\text { plate }\end{array}$ & $\begin{array}{l}\text { Uniform distribution in thickness } \\
\text { having } 3 \mathrm{D} \text { distribution with principal } \\
\text { alignment in flow direction of matrix, } \\
a_{11}=0.81, a_{22}=0.11 \text { and } a_{33}=0.08\end{array}$ & 20 & $72,0.22$ & $4.1,0.37$ & 0.1 \\
\hline 2 & $\begin{array}{l}\text { De } \\
\text { Monte et } \\
\text { al. }\end{array}$ & $\begin{array}{l}30 \% \text { wt. } \\
\text { GF } \\
\text { reinforced } \\
\text { PA } 6,6\end{array}$ & $\begin{array}{l}\text { Coupons are } \\
\text { milled in different } \\
\text { directions from a } \\
\text { plate }\end{array}$ & $\begin{array}{l}\text { Uniform distribution in thickness } \\
\text { having } 2 \mathrm{D} \text { distribution with principal } \\
\text { alignment in flow direction of matrix, } \\
a_{11}=0.79, a_{22}=0.20\end{array}$ & 26 & $72,0.22$ & $3.1,0.4$ & 0 \\
\hline 3 & $\begin{array}{l}\text { Klimkeit } \\
\text { et al. }\end{array}$ & $\begin{array}{l}30 \% \text { wt. } \\
\text { GF } \\
\text { reinforced } \\
\text { PET-PBT }\end{array}$ & $\begin{array}{l}\text { Coupons are } \\
\text { milled in different } \\
\text { directions from a } \\
\text { plate and a tube }\end{array}$ & $\begin{array}{l}\text { Variation of orientation in thickness } \\
\text { direction in both coupons milled from } \\
\text { plate and tube shaped. } \\
\text { Skin to core variation in the former, } \\
\text { better alignment in the latter. }\end{array}$ & 23 & $72,0.22$ & $4,0.35$ & 0.1 \\
\hline
\end{tabular}


The orientation distribution of the test coupons was different from the previous two cases (Jain et al. and De Monte et al.) in two significant ways. First, the orientation of fibers in KK-0, KK-45 and KK-90 are not predominantly in the same direction. The FOD in coupons used by Jain et al. and De Monte et al. were found to have relatively high degree of alignment in the matrix flow direction. However, there is a definite variation of the orientation in the thickness of the coupon leading to a "skin-core" variation in the coupons tested by Klimkeit et al. Also unlike the previous two cases, the orientations are different through the thickness of the coupon.

Secondly, the FOD of the tube and the coupons are distinct from each other. Unlike the previous two sets of validations, the FOD of the tube cannot be described by rotation of the FOD of the coupon. Validation of the MSNC and ss-MSNC will confirm the wide applicability of MSNC approach for a wide range of orientations for the input $\mathrm{SN}$ curve.

For each of the three sets of data only the SN curves are reproduced here in the results section; the data points are not shown since the goal of the MSNC is to predict the SN curve. Also, both De Monte et al. and Klimkeit et al. reported the mean stress, the MSNC method is used to calculate the peak stress. In this paper, the peak stress values have been calculated using the value of the applied load ratio that has been reported in the respective papers. For each result the $90 \%$ confidence intervals has also been plotted for reference and is shown by dotted lines.

\section{Results and discussion}

\subsection{Variance in the slope of SN curves}

The Student's t-test comparison of the slopes of the nine sets of published data is presented in Table 3. It was seen that the difference in slope for most of the published data is small and the Student's t-test for variance confirms that the difference in the slope is not significant for all but one of the fatigue data available. The difference in the slopes was found to be significant for only one fatigue data set (published by Bernasconi et al. [9]); it was found that while the 30, 60 and 90 degree coupon had similar slopes, the slope of the 0 -degree coupon was found to be statistically different to the other curves. It is thus concluded that it is reasonable to assume that the slopes of the SN curves are independent of the FOD though there might be some exceptions. 
Table 3 Summary of published data and t-test result for comparison of slopes of SN curves. PBT = Polybutylene terephthalate, $P A=$ Polyamide, $G F=$ glass fiber; the number after $G F$ indicates fiber weight fraction.

\begin{tabular}{|l|l|l|l|l|}
\hline $\begin{array}{l}\text { Sl. } \\
\text { No. }\end{array}$ & Material & Source of data & k-ratio range & $\begin{array}{l}\text { T-test result } \\
\text { Difference in slope is }\end{array}$ \\
\hline 1 & PBT-GF50 & Jain et al. [15] & $11.9-14.6$ & Not significant \\
\hline 2 & PA66-GF35 & De Monte et al. [6] & $15.4-17.2$ & Not significant \\
\hline 3 & PA6-GF30 & Bernasconi et al.[9] & $17.5-22.2$ & Significant \\
\hline 4 & PA6-GF30 & Horst et al. [5] & $12.4-12.4$ & Not significant \\
\hline 5 & PA6-GF33 & Wyzgoski et al. [47] & $13.9-14.0$ & Not Significant \\
\hline 6 & PBT-GF30 & Wyzgoski et al.[47] & $17.5-20.3$ & Not Significant \\
\hline 7 & PBT-GF30 & Klimkeit at al. [8] & $17.8-20.8$ & Not Significant \\
\hline 8 & PA66-GF30 & Arif et al. [10] & $17.0-25.0$ & Not Significant \\
\hline 9 & PA66- GF33 & Zhou and Mallick [48] & $15.1-18.5$ & Not Significant \\
\hline
\end{tabular}

\subsection{MSNC approach}

\subsubsection{Jain et al.}

The simulated results of the MSNC approach are shown in Figure 6. It was observed that the predicted SN curves correlate well to the experimental SN curves for the three simulations. In each of the three cases the predicted SN points in the curve are within the $90 \%$ confidence interval.

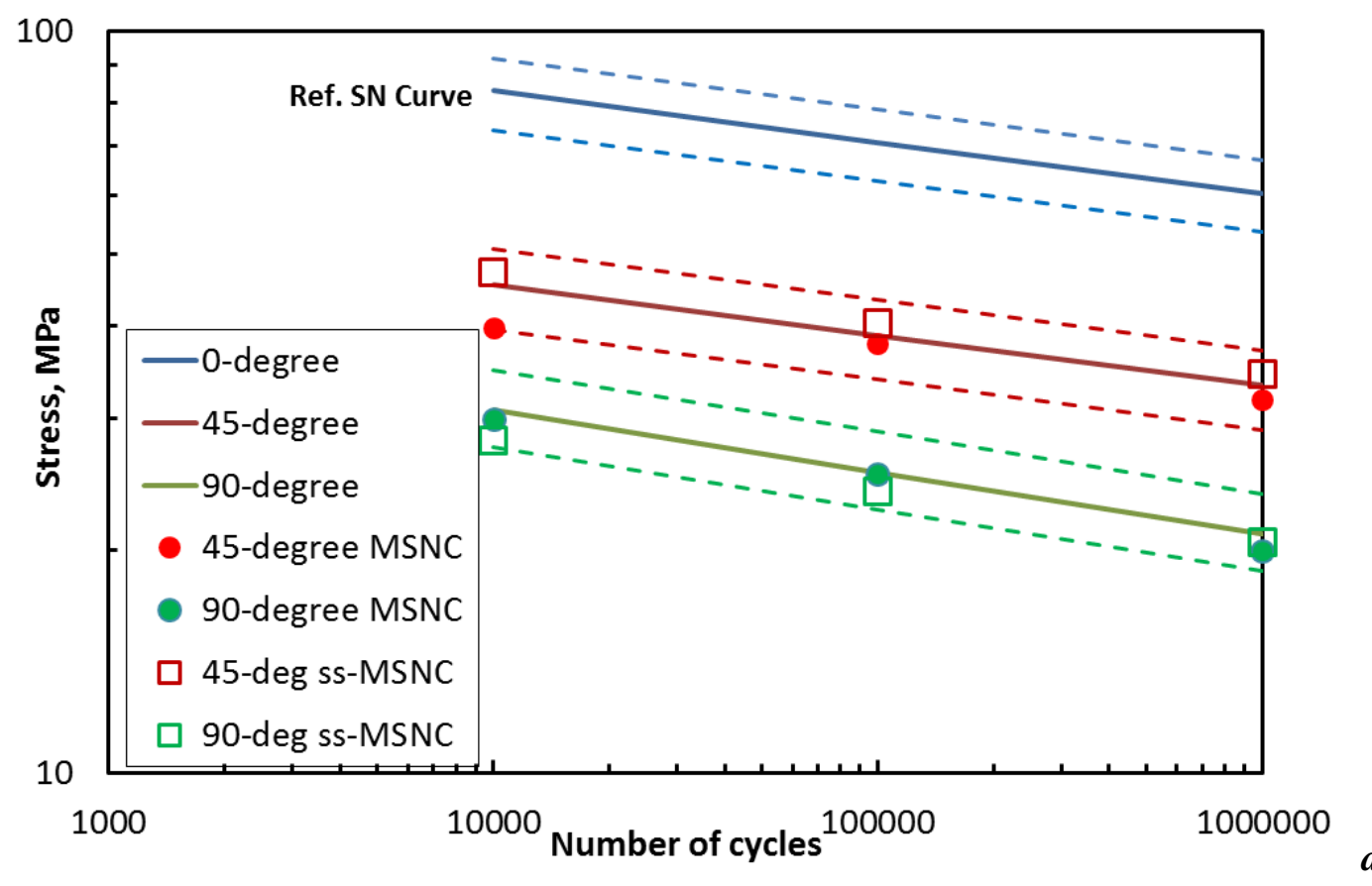



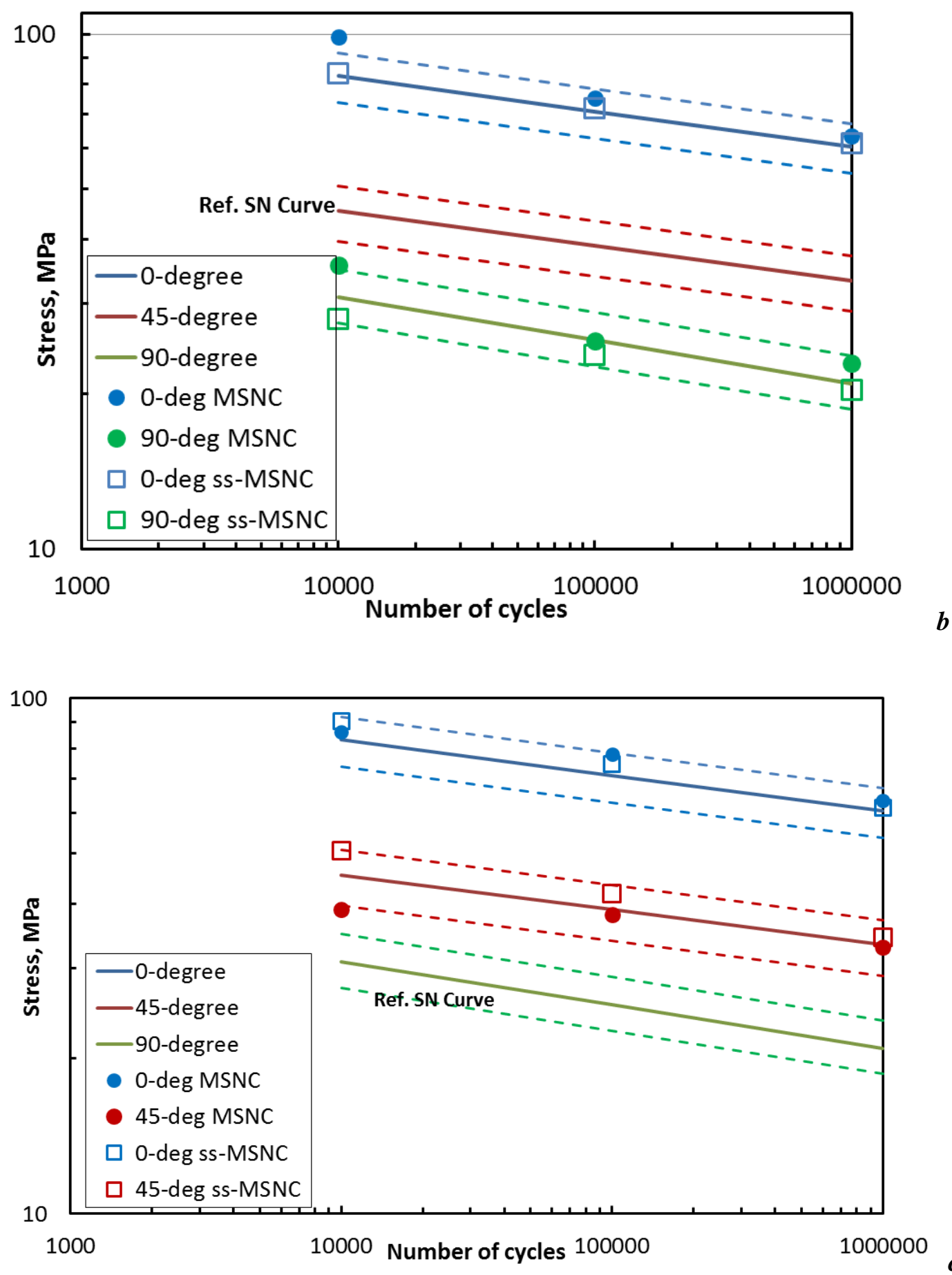

Figure 6 Predictions of the MSNC approach with one of the curves as the reference $S N$ curve and the other two are simulated. Hollow rectangular markers indicate the predicted data points by ss-MSNC scheme and circular markers are representative of the MSNC scheme. Data of Jain et al [15].

Reference SN curves: (a) 0-degree coupon (b) 45-degree coupon (c) 90-degree coupon 4.2.2 De Monte et al.

The results of the MSNC simulation for DM-0, DM-45 and DM-90 are shown in Figure 7. In general, good predictions of the fatigue points are seen. Though at low cycles, it is seen that predicted points sometimes lie outside the $90 \%$ confidence interval. 

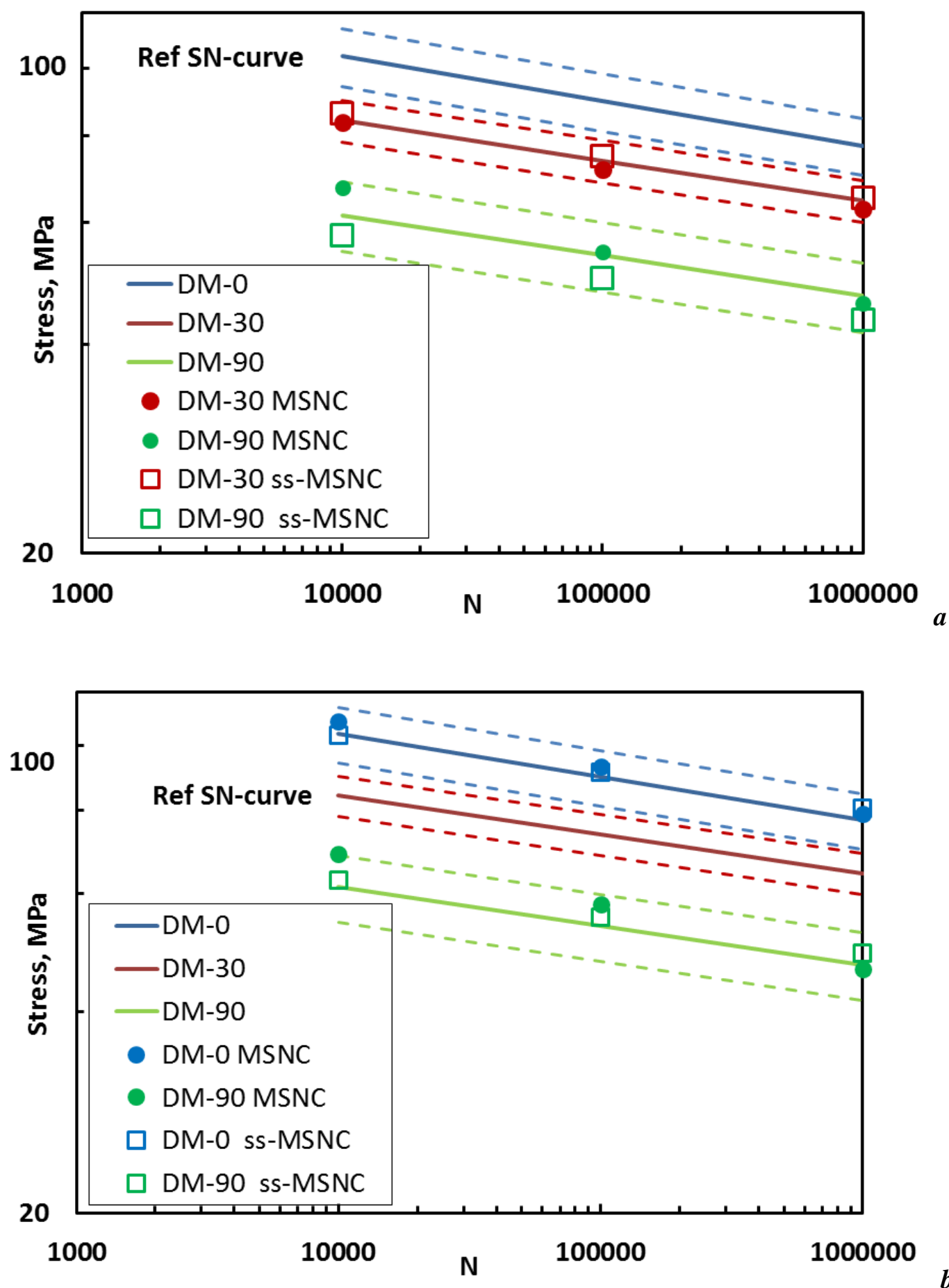


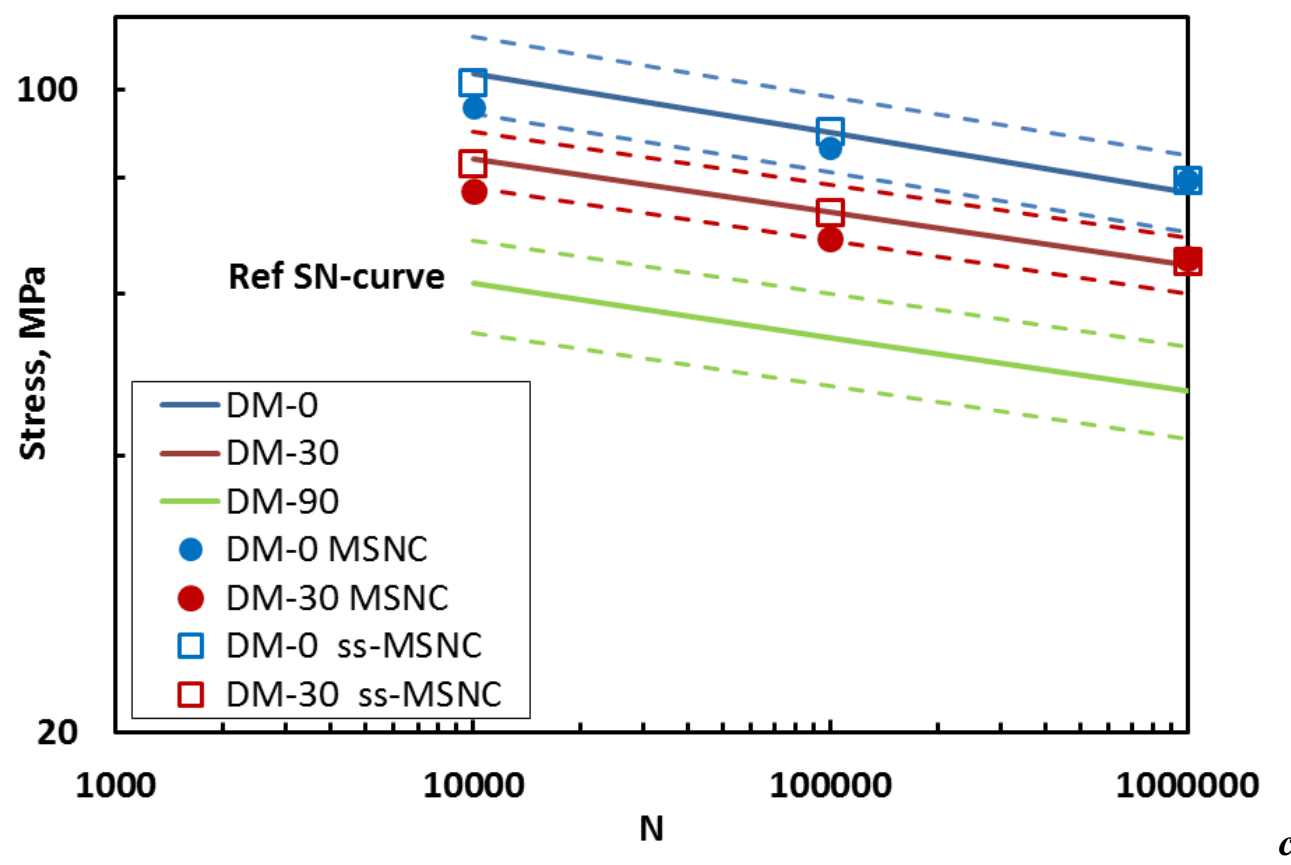

Figure 7 Predictions of the MSNC approach with one of the curves as the reference SN curve and the other two are simulated. Hollow rectangular markers indicate the predicted data points by ss-MSNC scheme and circular markers are representative of the MSNC scheme. Data of De Monte et al. [6,45]

Reference SN curve: (a) DM-O (b) DM-30 (c) DM-90

\subsubsection{Klimkeit et al.}

The results of the simulation for KK-tube, KK-0, KK-45 and KK-90 are presented in Figure 8. It is seen that the predictions of the MSNC are mostly within the $90 \%$ confidence interval but a couple of predictions at low cycles are outside the $90 \%$ interval.

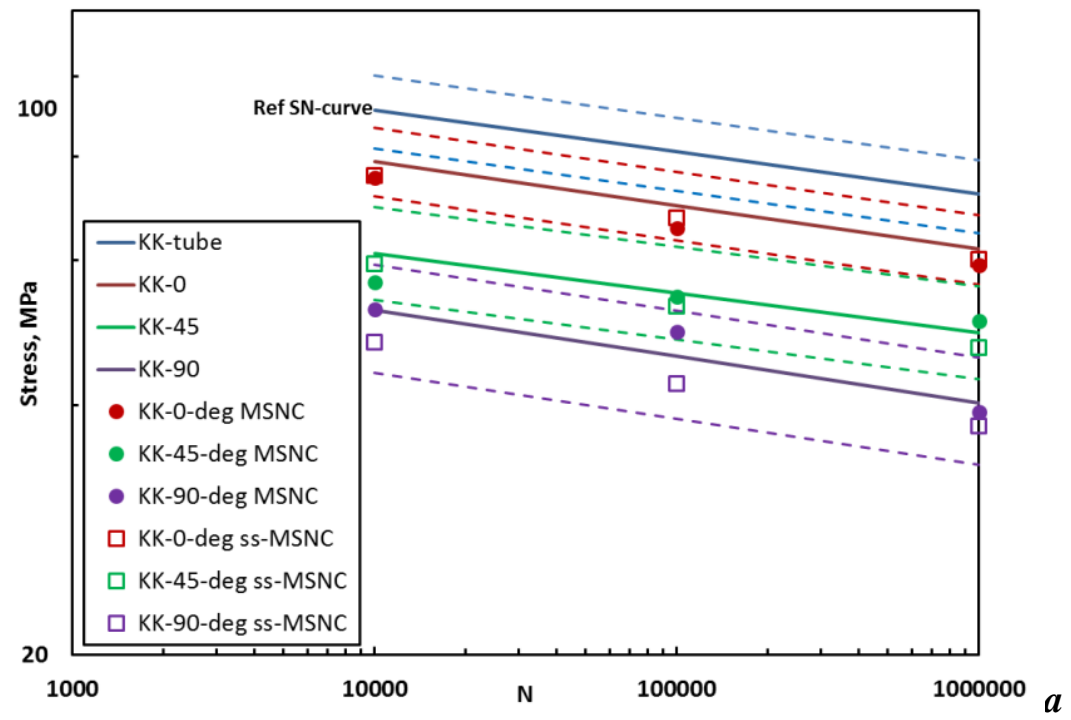



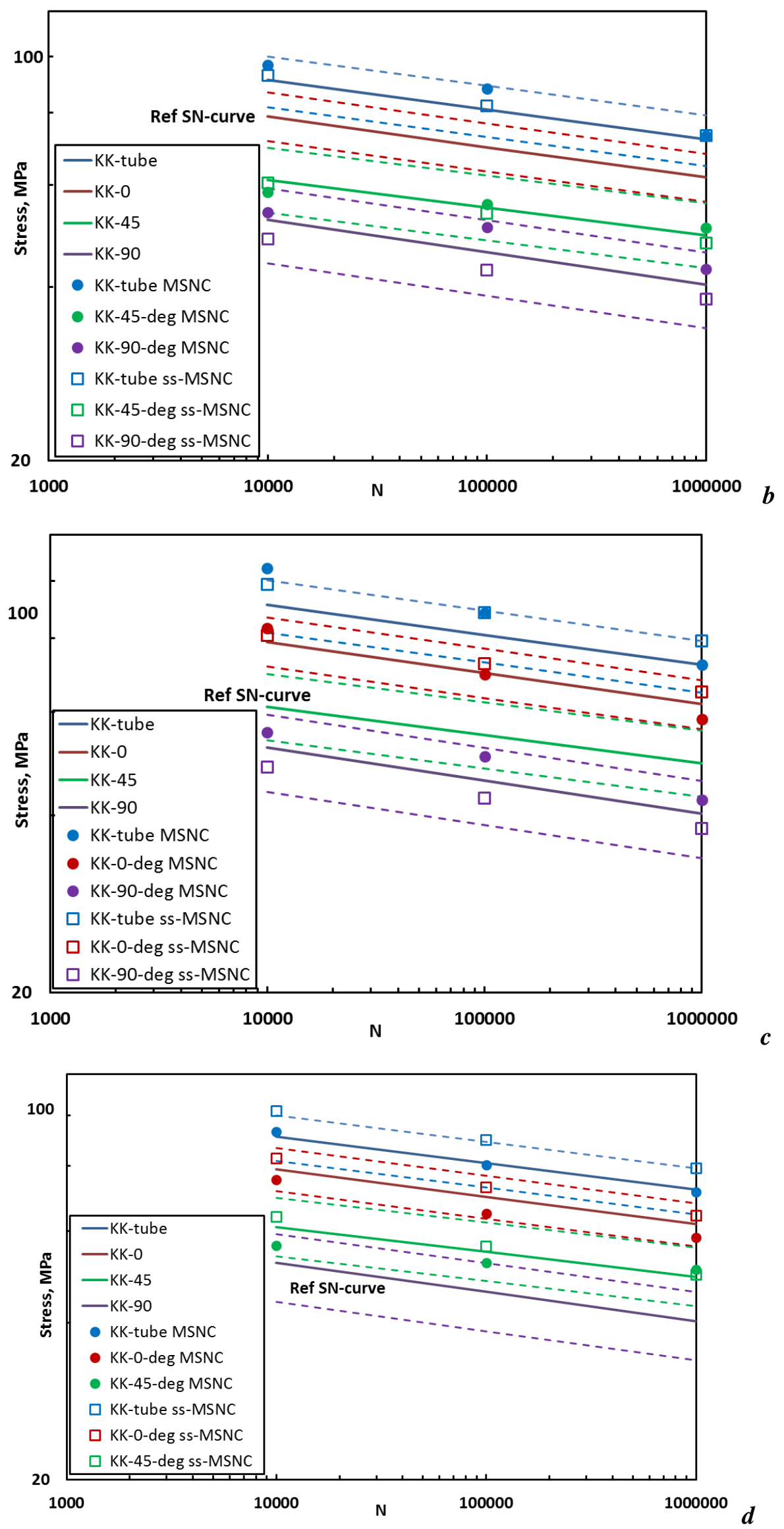
Figure 8 Predictions of the MSNC approach with one of the curves as the reference SN curve and the other two are simulated. Hollow rectangular markers indicate the predicted data points by ss-MSNC scheme and circular markers are representative of the MSNC scheme. Data of Klimkeit et al. [8]. Reference SN curve: (a) KK-tube, (b) KK-O, (c) KK-45, (d) KK-90

\subsection{Accuracy of the MSNC}

In this section the three sets of simulations (Jain et al., De Monte et al. and Klimkeit et al.) are grouped according to FOD and the number of cycles as input.

It is seen that the value of both the standard deviation and the mean of the absolute values of the error are similar for the three groups viz. 0, 45 and 90 degree SN curves as input (see Table 4). It was thus confirmed that neither the magnitude nor the variance of the errors of the MSNC approach depend on the FOD of the input SN curve.

When the errors of the MSNC approach are considered according to the number of cycles to failure, it is seen that the error progressively increases as the number of cycles to failure decreases. Increasing error in the low cycles (high loads) could be due to two reasons: the cumulative error during the micromechanics modelling increases as the applied load increases and second, it is possible that the assumptions made during the MSNC formulation are not valid in the low cycle fatigue region. This second possibility was confirmed by a statistical study of loss of stiffness curves presented in [29].

Table 4 Standard deviation and the mean of the error of MSNC approach for the three sets of simulations (corresponding to Jain et al., De Monte et al. and Klimkeit et al.)

\begin{tabular}{|c|c|c|c|c|}
\hline & Group & $\begin{array}{c}\text { No. of } \\
\text { samples }\end{array}$ & Mean \pm Std. dev. & $\begin{array}{c}\text { Mean of abs } \\
\text { (error) }\end{array}$ \\
\hline $\begin{array}{c}\text { Grouping according } \\
\text { to FOD }\end{array}$ & 0 -degree & 30 & $-0.02 \pm 0.062$ & 0.056 \\
\cline { 2 - 5 } & 45 -degree & 21 & $0.013 \pm 0.066$ & 0.048 \\
\cline { 2 - 5 } & 90 -degree & 21 & $-0.0035 \pm 0.045$ & 0.035 \\
\hline \multirow{2}{*}{$\begin{array}{c}\text { Grouping according } \\
\text { to number of cycles as } \\
\text { input }\end{array}$} & $10^{4}$ cycles & 24 & $-0.015 \pm 0.085$ & 0.069 \\
\cline { 2 - 5 } & $10^{5}$ cycles & 24 & $-0.001 \pm 0.044$ & 0.037 \\
\cline { 2 - 5 } & $10^{6}$ cycles & 24 & $-0.003 \pm 0.043$ & 0.036 \\
\hline
\end{tabular}


Finally the predictions of the ss-MSNC are compared and presented in Table 5.

Table 5 Comparison of the error in the SN curve points prediction by applying the MSNC at every point and applying the MSNC only at $10^{6}$ cycles and assuming same slope

\begin{tabular}{|c|c|c|c|c|c|}
\hline \multirow{2}{*}{ Group } & \multirow{2}{*}{$\begin{array}{l}\text { No. of } \\
\text { samples }\end{array}$} & \multicolumn{2}{|c|}{ MSNC } & \multicolumn{2}{c|}{$\begin{array}{c}\text { MSNC at } 10^{6} \text { cycles and } \\
\text { same slope assumption }\end{array}$} \\
\cline { 3 - 6 } & & Mean \pm Stdev. & $\begin{array}{c}\text { Mean of } \\
\text { abs(error) }\end{array}$ & $\begin{array}{c}\text { Mean } \pm \\
\text { Stdev. }\end{array}$ & $\begin{array}{c}\text { Mean of } \\
\text { abs(error) }\end{array}$ \\
\hline $10^{4}$ cycles & 24 & $0.016 \pm 0.085$ & 0.069 & $0.005 \pm 0.072$ & 0.062 \\
\hline $10^{5}$ cycles & 24 & $0.005 \pm 0.046$ & 0.037 & $0.003 \pm 0.057$ & 0.049 \\
\hline $10^{6}$ cycles & 24 & $0.003 \pm 0.043$ & 0.036 & $0.003 \pm 0.043$ & 0.037 \\
\hline
\end{tabular}

It is observed that applying the MSNC at only one point and then assuming the same slope reduces to some extent the error in the low cycle region (both the variance and mean of the absolute value of error). However the error in the group consisting of $10^{5}$ cycles was seen to increase marginally. Overall there seems to be no significant change in accuracy. It can thus be concluded that there are no disadvantages in terms of accuracy of applying the MSNC at only one point and then assuming the same slope. However some computational advantage can be achieved. Additionally the input required for applying the MSNC approach to only one point and assuming the same slope is less, the stress-strain curve of the pure matrix is no longer needed as input.

\section{Conclusions}

The MSNC approach has been validated using three sets of published data. It is seen that the MSNC approach can be used to get reasonable predictions of the SN curve, particularly in the high cycle region. An alternative approach to MSNC named same-slope MSNC has been proposed. It is seen that this approximate approach needs less input and is computationally cheaper. It was also confirmed that it is reasonable to assume that the slope of SN curves of SFRC is independent of the FOD. If the same slope assumption of SN curves is adopted, the only matrix related input is the yield stress of the matrix.

The FOD of the reference SN curve has no effect on the accuracy of the MSNC approach. Also, the MSNC method is applicable even if the coupons do not have the same FOD through the thickness and have a "skin-core variation" of FOD.

The accuracy of the MSNC has some dependency on the number of cycles taken as input. At lower number of cycles to failure, the error of the MSNC was seen to increase. 
The fact that limited test data is required could be a breakthrough in view of further industrial deployment of composite solutions in industry; since collection of fatigue data is often seen as a major bottleneck for industrial deployment. The ss-MSNC method has been implemented in the industrial software LMS Virtual.Lab Durability [49] part of Siemens PLM software [50].

The proposed MSNC approach (both variants) can be used to predict only the SN curves for uniaxial tension-tension loading and with R-ratio close to 0 , future work must be devoted to extending the MSNC to accommodate different applied load ratios as well as multi-axial loading.

\section{Acknowledgements}

The authors wish to thank the IWT Vlaanderen for funding this research as a part of the project "Fatigue life prediction of random fiber composites using hybrid multi-scale modelling methods" - COMPFAT Baekeland mandate number 100689. We also want to thank PART Engineering GmbH [51] for opening suitable interfaces in their software Converse to facilitate the analysis presented in this paper. Thanks also to Christophe Liefooghe, Dr. Michael Hack, Stefan Straesser and Dr. Frank Zingsheim from Siemens Industry Software NV for useful discussions and constructive feedback. I. Verpoest and S.V. Lomov are holders of the Toray Chair in Composites at KULeuven.

\section{References}

[1] Mortazavian S, Fatemi A. Fatigue behavior and modeling of short fiber reinforced polymer composites: A literature review. Int J Fatigue 2015;70:297-321. doi:10.1016/j.ijfatigue.2014.10.005.

[2] Fara S, Pavan A. Fibre orientation effects on the fracture of short fibre polymer composites: on the existence of a critical fibre orientation on varying internal material variables. J Mater Sci 2004;39:3619-28. doi:10.1023/B:JMSC.0000030714.13161.f6.

[3] Hine PJ, Duckett RA. Fiber orientation structures and mechanical properties of injection molded short glass fiber reinforced ribbed plates. Polym Compos 2004;25:237-54. doi:10.1002/pc.20019.

[4] Zhou H. Computer Modeling for Injection Molding: Simulation, Optimization, and Control. Wiley; 2013.

[5] Horst JJ, Spoormaker JL. Mechanisms of fatigue in short glass fiber reinforced polyamide 6. Polym Eng Sci 1996;36:2718-26. doi:10.1002/pen.10671.

[6] De Monte M, Moosbrugger E, Quaresimin M. Influence of temperature and thickness on the off-axis behaviour of short glass fibre reinforced polyamide 6.6 cyclic loading. Compos Part A Appl Sci Manuf 2012;41:1368-79. doi:http://dx.doi.org/10.1016/j.compositesa.2010.02.004.

[7] Horst JJ, Spoormaker JL. Fatigue fracture mechanisms and fractography of short- 
glassfibre-reinforced polyamide 6. J Mater Sci 1997;32:3641-51. doi:10.1023/a:1018634530869.

[8] Klimkeit B, Nadot Y, Castagnet S, Nadot-Martin C, Dumas C, Bergamo S, et al. Multiaxial fatigue life assessment for reinforced polymers. Int J Fatigue 2011;33:76680. doi:10.1016/j.ijfatigue.2010.12.004.

[9] BERNASCONI A, Davoli P, Basile A, FILIPPI A. Effect of fibre orientation on the fatigue behaviour of a short glass fibre reinforced polyamide-6. Int $\mathrm{J}$ Fatigue 2007;29:199-208. doi:http://dx.doi.org/10.1016/j.ijfatigue.2006.04.001.

[10] Arif MF, Saintier N, Meraghni F, Fitoussi J, Chemisky Y, Robert G. Multiscale fatigue damage characterization in short glass fiber reinforced polyamide-66. Compos Part BEngineering 2014;61:55-65. doi:10.1016/j.compositesb.2014.01.019.

[11] Zago A, Springer GS. Constant amplitude fatigue of short glass and carbon fiber reinforced thermoplastics. J Reinf Plast Compos 2001;20:564-95. doi:10.1106/actdcl49-v4ga-4dyj.

[12] Zago A, Springer GS. Fatigue lives of short fiber reinforced thermoplastics parts. J Reinf Plast Compos 2001;20:606-20. doi:10.1106/8u2g-bc07-3jtj-02mp.

[13] Guster C, Pinter G, Mosenbacher A, Eichlseder W. Evaluation of a Simulation Process for Fatigue Life Calculation of Short Fibre Reinforced Plastic Components. 11th Int Conf Mech Behav Mater 2011;10:6. doi:10.1016/j.proeng.2011.04.348.

[14] Mortazavian S, Fatemi A. Fatigue behavior and modeling of short fiber reinforced polymer composites including anisotropy and temperature effects. Int $\mathrm{J}$ Fatigue 2015;77:12-27. doi:10.1016/j.ijfatigue.2015.02.020.

[15] Jain A, Beas J, Van Paepegem W, I. V, Lomov S. The Master SN curve approach - A hybrid multiscale approach towards fatigue simulation of short fiber reinforced composites. Compos Part A Appl Sci Manuf 2015. doi:doi:10.1016/j.compositesa.2015.11.038.

[16] Jain A, Verpoest I, Hack M, Lomov S, Adam L, Van Paepegem W. Fatigue Life Simulation on Fiber Reinforced Composites - Overview and Methods of Analysis for the Automotive Industry. SAE Int J Mater Manuf 2012;5:205-14. doi:10.4271/2012-010730 .

[17] Mori T, Tanaka K. Average Stress in Matrix and Average Elastic Energy of Materials with Misfitting Inclusions. Acta Metall 1973;21:571-4.

[18] Bernasconi A, Davoli P, Rossin D, Armanni C. Effect of reprocessing on the fatigue strength of a fibreglass reinforced polyamide. Compos Part a-Applied Sci Manuf 2007;38:710-8. doi:10.1016/j.compositesa.2006.09.012.

[19] Klimkeit B, Bergamo S, Nadot Y, Castagnet S, Dumas C. Multiaxial fatigue behavior of short-fiber reinforced thermoplastic roof bars. ICMFF9, 2013.

[20] Arif MF, Meraghni F, Chemisky Y, Despringre N, Robert G. In situ damage mechanisms investigation of PA66/GF30 composite: Effect of relative humidity. Compos Part BEngineering 2014;58:487-95. doi:10.1016/j.compositesb.2013.11.001.

[21] Fitoussi J, Bocquet M, Meraghni F. Effect of the matrix behavior on the damage of ethylene-propylene glass fiber reinforced composite subjected to high strain rate tension. Compos Part B Eng 2013;45:1181-91. doi:10.1016/j.compositesb.2012.06.011.

[22] O'Gara John F, Novak Glen E, Wyzgoski MG. Predicting the tensile strength of short glass fiber reinforced injection molded plastic. Proc. 10th Annu. SPE Automot. Compos. 
Conf. Expo. ACCE, 2010.

[23] Meneghetti G, Quaresimin M. Fatigue strength assessment of a short fiber composite based on the specific heat dissipation. Compos Part B Eng 2010;42:217-25. doi:http://dx.doi.org/10.1016/j.compositesb.2010.12.002.

[24] Jegou L, Marco Y, Le Saux V, Calloch S. Fast prediction of the Wohler curve from heat build-up measurements on Short Fiber Reinforced Plastic. Int J Fatigue 2013;47:259-67. doi:10.1016/j.ijfatigue.2012.09.007.

[25] Vervoort S. Fatigue Analysis of polymer components with short fiber reinforcements. NAFEMS World Congr 2013.

[26] Malo T, Adam L, Assaker R, Matsumoto T, Giacomini R. Multi-scale modeling of high cycle fatigue of chopped and continuous fiber composites. SPEAutomotive 2013.

[27] Erhard G. Designing with polymers. Carl Hanser Publishing, Munich/Vienna; 1999.

[28] Mosenbacher A, Brunbauer J, Pichler PF, Guster C, Pinter G. Modelling and validation of fatigue life calculation method for short fiber reinforced injection molded parts. 16th Eur Conf Compos Mater 2014.

[29] Jain A, Van Paepegem W, Verpoest I, Lomov S V. On the loss of stiffness during cyclic loading for short fiber reinforced injection molded composites. To Be Submitt to Compos Part B n.d.

[30] Benveniste Y. A new approach to the application of mori-tanaka theory in compositematerials. Mech Mater 1987;6:147-57. doi:10.1016/0167-6636(87)90005-6.

[31] Jain A, Lomov S V., Abdin Y, Verpoest I, Van Paepegem W. Pseudo-grain discretization and full Mori Tanaka formulation for random heterogeneous media: Predictive abilities for stresses in individual inclusions and the matrix. Compos Sci Technol 2013;87:8693. doi:10.1016/j.compscitech.2013.08.009.

[32] Jain A, Abdin Y, Van Paepegem W, Verpoest I, Lomov S V. Effective anisotropic stiffness of inclusions with debonded interface for Eshelby-based models. Compos Struct 2015;131:692-706. doi:10.1016/j.compstruct.2015.06.007.

[33] Jain A, Abdin Y, Van Paepegem W, Verpoest I, Lomov S V. Non-symmetric stiffness tensor prediction by the Mori-Tanaka scheme - Comments on the article "Effective anisotropic stiffness of inclusions with debonded interface for Eshelby-based models, Comp. Structures 131 (2015) 692-706." Compos Struct 2015. doi:10.1016/j.compstruct.2015.08.140.

[34] Tandon GP, Weng GJ. A theory of particle-reinforced plasticity. J Appl Mech Asme 1988;55:126-35.

[35] Huysmans G, Verpoest I, Van Houtte P. A damage model for knitted fabric composites. Compos Part a-Applied Sci Manuf 2001;32:1465-75. doi:10.1016/s1359835x(01)00045-8.

[36] Cox HL. The elasticity and strength of paper and other fibrous materials. Br J Appl Phys 1952;3:72-9. doi:10.1088/0508-3443/3/3/302.

[37] Bernasconi A, Davoli P, Basile A, Filippi A. Effect of fibre orientation on the fatigue behaviour of a short glass fibre reinforced polyamide-6. Int J Fatigue 2007;29:199-208. doi:10.1016/j.ijfatigue.2006.04.001.

[38] Launay A, Maitournam MH, Marco Y, Raoult I. Multiaxial fatigue models for short glass fiber reinforced polyamide - Part I: Nonlinear anisotropic constitutive behavior for cyclic 
response. Int J Fatigue 2013;47:382-9. doi:10.1016/j.ijfatigue.2012.03.012.

[39] Schneider CRA, Maddox SJ. Best practice guide on statistical analysis of fatigue data. Weld Inst Stat Rep 2003.

[40] Onat ET, Leckie FA. Representation of mechanical behavior in the presence of change internal structure. Trans ASME J Appl Mech 1988;55:1-10.

[41] PLASTICS C. CAMPUS $®$ - a material information system for the plastics industry 2014. doi:http://www.campusplastics.com/.

[42] Advani SG, Tucker CL. The use of tensors to describe and predict fiber orientation in short fiber composites. J Rheol (N Y N Y) 1987;31:751-84. doi:10.1122/1.549945.

[43] Schjodt-Thomsen J, Pyrz R. The Mori-Tanaka stiffness tensor: diagonal symmetry, complex fibre orientations and non-dilute volume fractions. Mech Mater 2001;33:53144. doi:http://dx.doi.org/10.1016/S0167-6636(01)00072-2.

[44] Sigmasoft. SIGMA Engineering GmbH, Aachen. Http://www.sigmasoft.de/ 2014. doi:http://www.sigmasoft.de/.

[45] De Monte M, Moosbrugger E, Quaresimin M. Influence of temperature and thickness on the off-axis behaviour of short glass fibre reinforced polyamide 6.6-Quasi-static loading. Compos Part a-Applied Sci Manuf 2010;41:1368-79. doi:http://dx.doi.org/10.1016/j.compositesa.2010.02.004.

[46] www.autodesk.com/moldflow, editor. Autodesk Moldflow 2014. doi:www.autodesk.com/moldflow.

[47] Wyzgoski MG, Krohn JA, Novak GE. Fatigue of fiber-reinforced injection molded plastics. I: Stress-lifetime data. Polym Compos 2004;25:489-98. doi:10.1002/pc.20042.

[48] Zhou YX, Mallick PK. Fatigue performance of an injection-molded short E-glass fiberreinforced polyamide 6,6. I. Effects of orientation, holes, and weld line. Polym Compos 2006;27:230-7. doi:10.1002/pc.20182.

[49] http://www.plm.automation.siemens.com/en_us/products/lms/virtual-lab/durability/, editor. LMS Virtual.Lab Durability-Durability analysis for optimal product performance 2015. doi:http://www.plm.automation.siemens.com/en_us/products/lms/virtuallab/durability/.

[50] www.siemens.com/plm, editor. Siemens PLM software. Www.siemens.com/plm 2015. doi:www.siemens.com/plm.

[51] http://www.part-gmbh.de/, editor. PART Engineering. Http://www.part-Gmbh.de/ 2015. doi:http://www.part-gmbh.de/. 